\title{
Mineração
}

\section{Influência da expansão urbana nos movimentos em encostas na cidade de Ouro Preto, MG}

\author{
Antônio Luiz Pinheiro \\ Doutorando em Geologia/Programa de Pós-Graduação em Recursos Naturais e Evolução Crustal \\ E-mail:pinheiro@degeo.ufop.br \\ Frederico Garcia Sobreira \\ Professor Adjunto do Departamento de Geologia/Escola de Minas/UFOP \\ E-mail:sobreira@degeo.ufop.br \\ Milene Sabino Lana \\ Professora Adjunta do Departamento de Engenharia de Minas/Escola de Minas/UFOP \\ E-mail:milene@demin.ufop.br
}

\section{Resumo}

A cidade de Ouro Preto enfrenta hoje grandes problemas, no tocante à sua expansão e crescimento urbano, devido à carência de áreas em condições adequadas para construção, sob o ponto de vista geotécnico. Atualmente Ouro Preto sofre as consequiências da ocupação inadequada do espaço urbano, em função do povoamento excessivo, da falta de áreas para expansão e da concentração da população de baixa renda em torno dos rios, córregos e zonas da periferia do núcleo urbano. Até mesmo, na região central, que é ocupada por pessoas de melhores condições sócio-econômicas, a negligência quanto ao risco de movimentos em encostas é notória. O presente artigo discute essa questão apresentando, em particular, o problema de ocupação de encostas no Morro do Curral.

Palavras-chave: expansão urbana, movimentos em encostas, Ouro Preto.

\begin{abstract}
Nowadays the city of Ouro Preto is faced with large problems relating to its expansion and urban increase, due to the lack of places with adequate geothecnical conditions for building. The city has been facing the consequences of inadequate occupation of the urban environment due to excessive inhabitation, lack of areas for urban expansion and the concentration of poor people around the rivers, brooks and the surroundings. Even in the central area, which is occupied by people with good social-economical conditions, the neglect of the risk of landslides is evident. This paper discusses this question, presenting in particular the problem of occupation of Morro do Curral hill.
\end{abstract}

Keywords: urban expansion, landslides, Ouro Preto. 


\section{Introdução}

Desde o início do século XVII, a cidade de Ouro Preto enfrenta problemas com a ocorrência de deslizamentos em encostas na região urbana. No início de seu povoamento, a ocupação buscou incorporar os poucos espaços planos existentes entre seus córregos e montanhas. Foram ocupadas inicialmente as áreas mais estáveis e planas, como o topo das colinas e platôs a meia encosta, cume dos morros e vales mais largos, locais onde estão erguidas igrejas e grandes construções históricas.

A partir de 1945, quando se dá a primeira corrida de alumínio e principalmente depois de 1950, tem início um grande crescimento populacional na cidade. O núcleo urbano principal, que se mantinha praticamente inalterado desde os fins do século XVIII, sofre um processo de expansão, sendo aproveitadas todas as áreas da periferia que oferecem condições razoáveis.

De acordo com Sobreira e Fonseca (2001), a necessidade de criação de novas áreas urbanas em função do crescimento da população, a partir dos anos sessenta não foi acompanhada por planejamento prévio adequado, levando à ocupação de áreas onde se desenvolveram atividades de mineração no passado. Na maioria das vezes essas áreas apresentam características morfológicas e geotécnicas desfavoráveis, gerando, assim, um quadro problemático no que se refere à segurança da população e das estruturas presentes nessas áreas.

Nas décadas de 80 e 90, presenciase o surgimento de novos bairros, como Pocinho e Santa Cruz, ambos sem qualquer planejamento, o que reforça que, mesmo nos dias atuais, o descaso do poder público permanece, no que diz respeito à ocupação desordenada do espaço urbano.

Segundo Fernandes (2000), atualmente a cidade carece do uso do conhecimento das propriedades e das características dos seus terrenos de forma a se desenvolver harmonicamente, viabilizando um crescimento ordenado num espaço geotecnicamente inadequado. Esses riscos estão ligados à susceptibilidade natural das encostas a movimentos de massa, associados a uma ocupação desordenada e a outros fatores, tais como baixo poder aquisitivo da população e ausência de melhores tecnologias na construção civil. As transformações sofridas pela cidade, em função dos assentamentos urbanos crescentes, interferiram de maneira acelerada e intensa na estabilidade das encostas.

Esse trabalho apresenta uma discussão sucinta a respeito do problema de ocupação de encostas na cidade, enfatizando o problema de ocupação da encosta do Morro do Curral, área onde já foram desenvolvidos estudos geotécnicos (Fernandes, 2000, Pinheiro, 2002) que descrevem e caracterizam problemas de ruptura em diversos setores da encosta.

\section{O Morro do Curral \\ 2.1 Localização e geologia}

O Morro do Curral (Figura 1) situase a oeste da praça Tiradentes, no eixo histórico da cidade de Ouro Preto e estende-se desde o Bairro Jardim Alvorada, divisando com o Bairro Vila São José, Praça Rio Branco, até a Praça Cesário Alvim (onde se localiza o prédio da antiga estação ferroviária). O Morro do Curral pode ser visto de todo o centro histórico por turistas e ou moradores da cidade de Ouro Preto, o que ocasiona um grande impacto visual por causa dos problemas de rupturas.

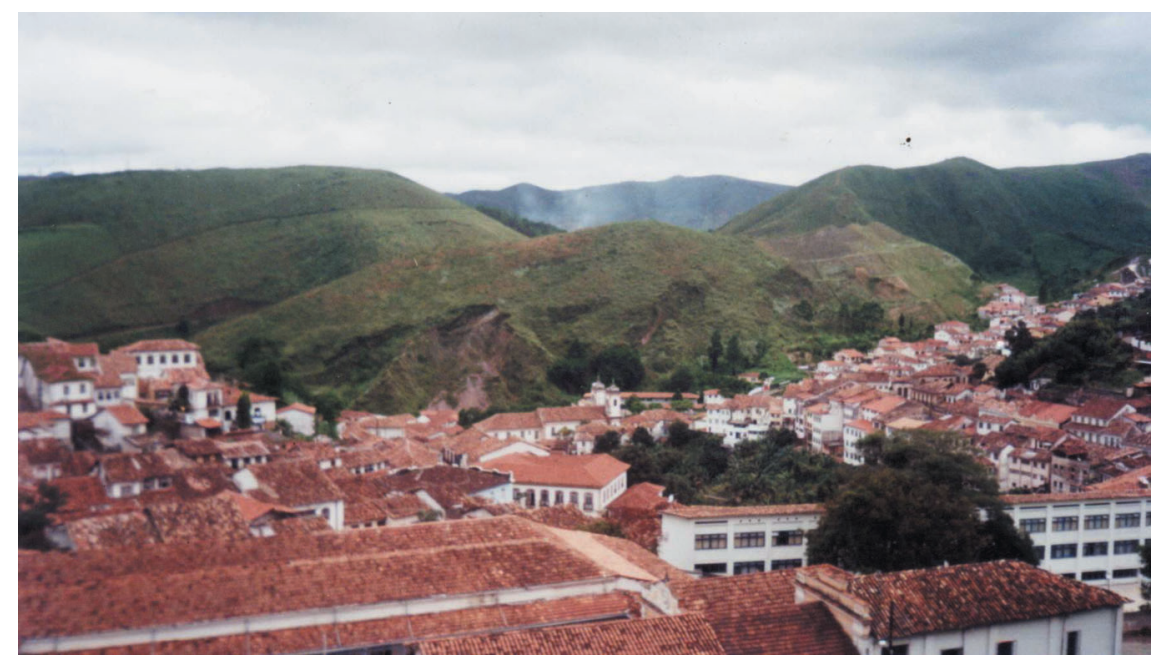

Figura 1 - Vista geral do Morro do Curral.
O maciço rochoso do Morro do Curral encontra-se no Grupo Sabará do Supergrupo Minas. Regionalmente a litologia é complexa e sua espessura variada. Na ocorrência típica, é composta de filitos, xistos, lentes subordinadas de grauvacas ou subgrauvacas, tufos metamorfoseados e camadas finas de quartzito, localmente rico em ferro (Dorr II, 1969).

\subsection{Histórico da área}

No Morro do Curral existem sinais evidentes de movimentos de massa ocorridos no passado e também indícios de possíveis movimentos que estão acontecendo no presente, como aqueles que poderão vir a acontecer no futuro, como mostra trabalho executado em áreas dessa encosta por Fernandes (2000) e Pinheiro (2002).

Dos movimentos de massa ocorridos no passado, o de maior importância foi o de 1979 (Figura 2), a montante do bairro Vila São José, com um volume aproximado de $100.000 \mathrm{~m}^{3}$ de material. Esse acidente motivou a execução de obras de terraplanagem com o objetivo de remover o material rompido e alterar a geometria da encosta, de forma a aumentar sua estabilidade.

O escorregamento se deu no xisto do Grupo Sabará e foi causado pela erosão da base da encosta, onde aflorava o quartzito Taboões bem alterado e friável (Sobreira et al., 1990). 
O projeto de suavização da encosta, elaborado pela empresa Tecnosolo em junho de 1979, envolveu a remoção de $600.000 \mathrm{~m}^{3}$ de material (Figura 3), que foi depositado sobre o antigo depósito de efluentes, com alto teor de soda, resultante do tratamento da bauxita para obtenção de alumínio.

$\mathrm{Na}$ época optou-se por essa solução por se tratar de uma alternativa mais viável entre as analisadas, uma vez que não haveria necessidade de transitar com caminhões carregados de material pelo centro histórico, danificando o calçamento das ruas e abalando as estruturas do acervo histórico da cidade. Com essa alternativa, foi possível também a abertura de uma comunicação entre o centro histórico e uma área em expansão (hoje Bairro Jardim Alvorada), além da possibilidade de recuperação de uma área degradada (o antigo lago de lama).

Atualmente observa-se no local a interferência na obra de retaludamento pelas construções executadas na base da encosta. Cabe salientar que pelo porte das edificações que foram e estão sendo erguidas não se trata de proprietários de baixo poder aquisitivo, o que sempre é dado como desculpa para invasões e construções em áreas de risco.

Na base da encosta Morro do Curral, em área estudada por Fernandes (2000), encontram-se as instalações do Centro de Artes e Convenções de Ouro Preto (Figura 4), uma grande estrutura de eventos, onde são sediados congressos, convenções, núcleos de artes e criações, seminários, reuniões, conferências e eventos similares, com infraestrutura de atendimento para até 600 pessoas.

Encontra-se também instalada na base da encosta do Morro do Curral a Escola Estadual Dom Velloso, escola tradicional no ensino fundamental da cidade de Ouro Preto.

Além dessas duas construções, que merecem destaque pelo seu porte $\mathrm{e}$ quantidade de pessoas envolvidas, no sopé da encosta situam-se dezenas de residências, farmácia, padaria, bares, etc.

\section{Estudo de caso em um talude no Morro do Curral}

No trabalho desenvolvido por Fernandes (2000), foi estudada a encosta a montante do Centro de Artes e Convenções de Ouro Preto. As rupturas foram identificadas e soluções para sua estabilização foram propostas.

Outro trabalho executado no Morro do Curral foi desenvolvido por Pinheiro (2002); nesse trabalho foi estudada a encosta situada a montante da Praça Rio Branco. Alguns dos principais resultados desse trabalho são apresentados em seguida.

\subsection{Caracterização da área}

Nessa etapa foi feito o reconhecimento de todo o Morro do Curral. Esse levantamento teve como objetivo delimitar uma área específica de maior interesse, onde foram executados os trabalhos de levantamento de campo.

Depois do reconhecimento de todo o Morro do Curral, foi escolhida uma área adjacente à estudada por Fernandes (2000), de grande complexidade geológica, com presença de dobramentos que influenciam diretamente os mecanismos de ruptura observados.

A área escolhida (Figura 5) situase a montante da Praça Barão do Rio

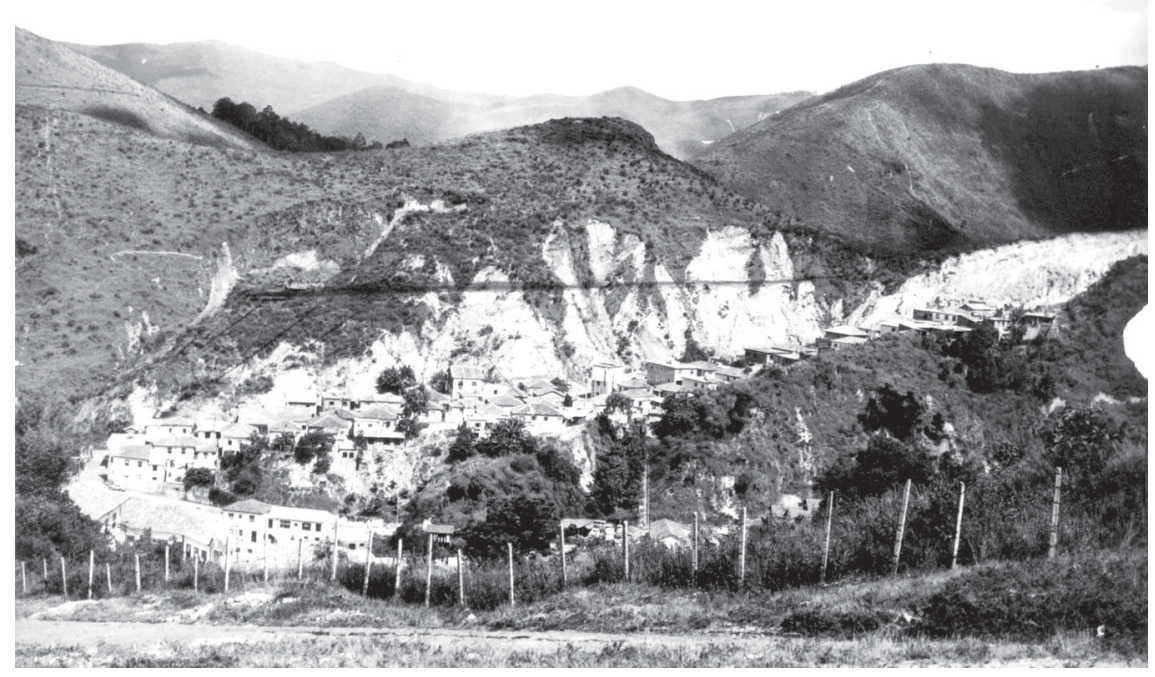

Figura 2 - Movimento de massa ocorrido em 1979. Fonte: IPHAN.

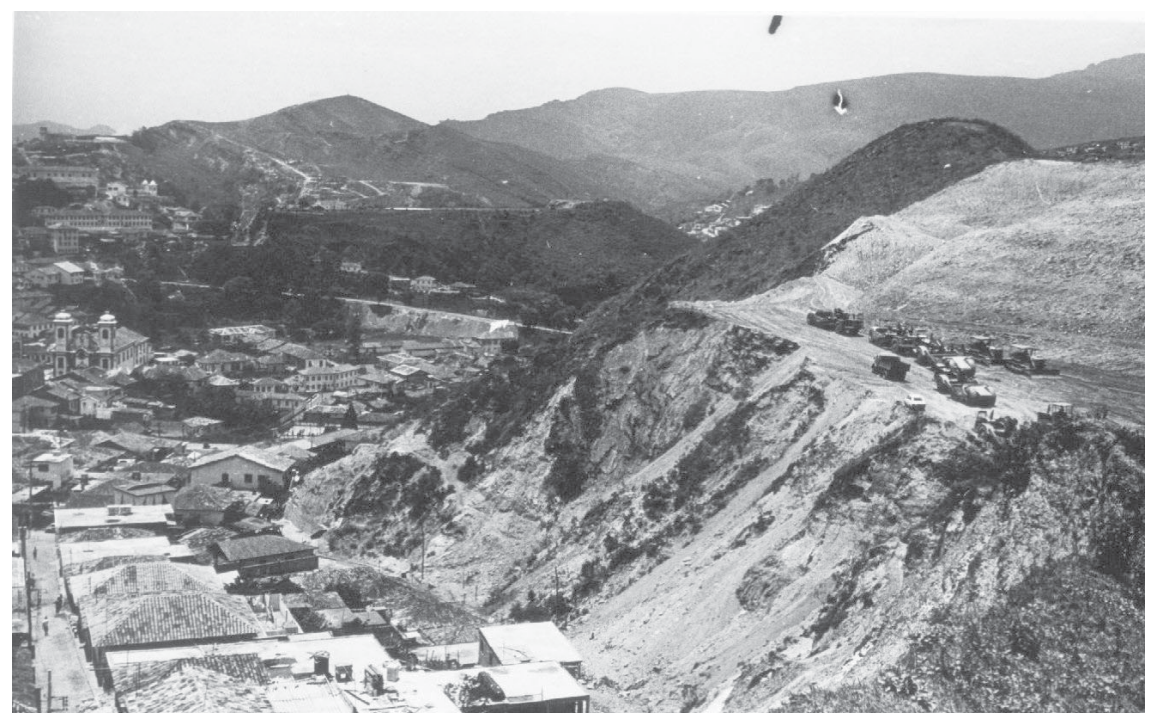

Figura 3 - Obras de retaludamento na encosta Vila São José (1980). Fonte: IPHAN. 
Branco atrás da igreja Matriz Nossa Senhora do Pilar, uma das importantes relíquias do acervo da cidade de Ouro Preto, monumento mundial.

No sopé da encosta há um depósito de tálus com inclinação de $45^{\circ}$. Esse depósito possui pouquíssima cobertura vegetal, é composto por blocos de xisto de tamanho decimétrico a métrico, envolvidos por uma matriz de material fino (silte). Houve movimentação recente (janeiro, 2003), o que acarretou o deslizamento de material sobre as áreas de serviço das residências que se localizam na base da encosta. Essas áreas de serviços foram construídas a partir do capeamento do córrego Caquende, que corta a base da encosta, e de cortes executados no depósito de tálus pelos próprios moradores.

Acima do depósito de tálus encontram-se as três cicatrizes de rupturas que foram estudadas em nível de detalhe, desenvolvidas numa porção do Xisto Sabará. Essas cicatrizes geraram e continuam gerando material para o depósito de tálus e também geram finos que são carreados para o córrego Caquende, através das duas drenagens laterais.

\subsection{Levantamento de detalhe}

No levantamento de detalhe foram medidas as atitudes das descontinuidades que originaram as rupturas, bem como as dimensões das cicatrizes relacionadas às rupturas. Observou-se que as cicatrizes são subparalelas. As rupturas foram condicionadas pela xistosidade $\mathrm{e}$ por duas famílias de fraturas. O mapa geotécnico do local, gerado por Pinheiro (2002), é mostrado na Figura 6.

Para definição das famílias de fraturas que condicionam os movimentos observados, foi feito o levantamento geotécnico para obtenção dos valores de atitudes médias das famílias. Com os dados obtidos do levantamento foram identificadas três famílias de fraturas $(1 \mathrm{~m}$ : 041/71, 2m: 285/87 e 3m: 343/74), ver Figura 7. As famílias $1 \mathrm{~m}$ e $2 \mathrm{~m}$ geraram os blocos que deram origem às cicatrizes. Já a família $3 \mathrm{~m}$ está localizada dentro das cicatrizes.

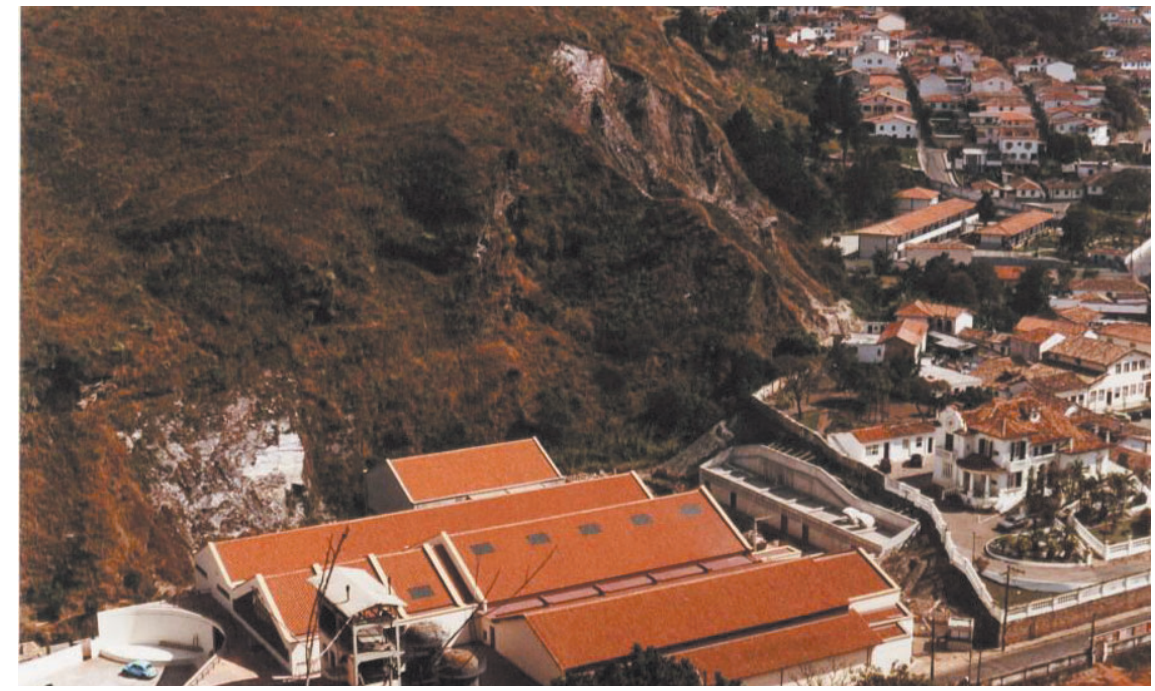

Figura 4 - Construções na base do Morro do Curral.

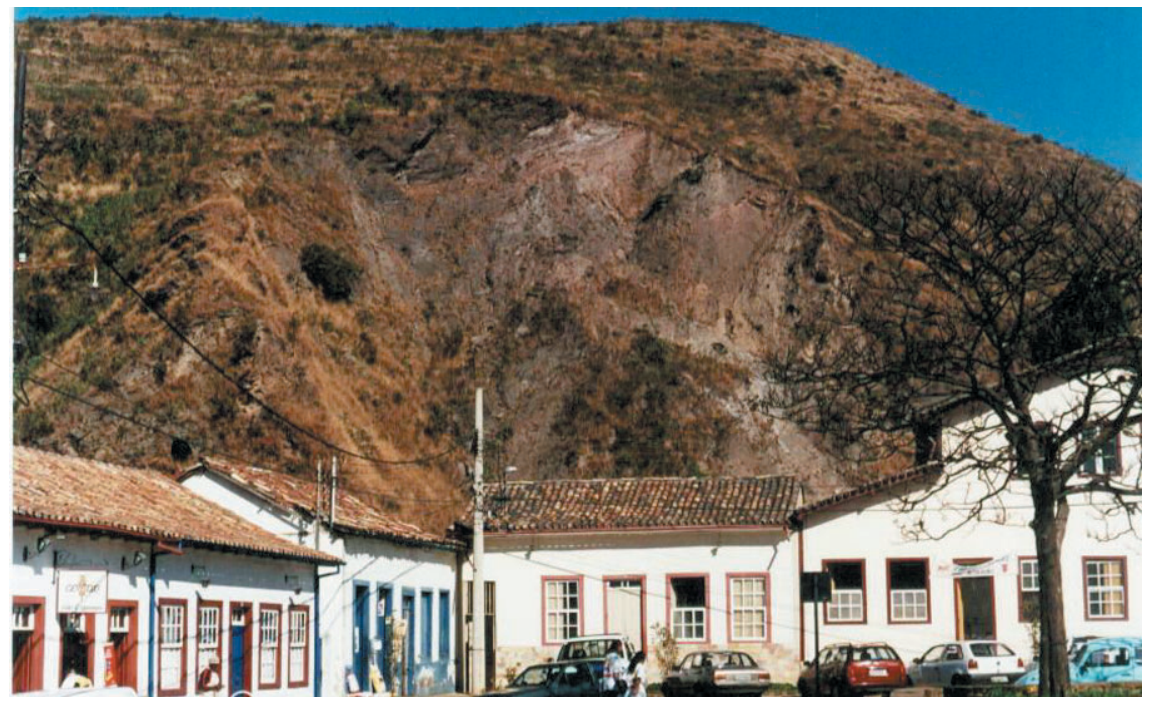

Figura 5 - Vista da encosta estudada.

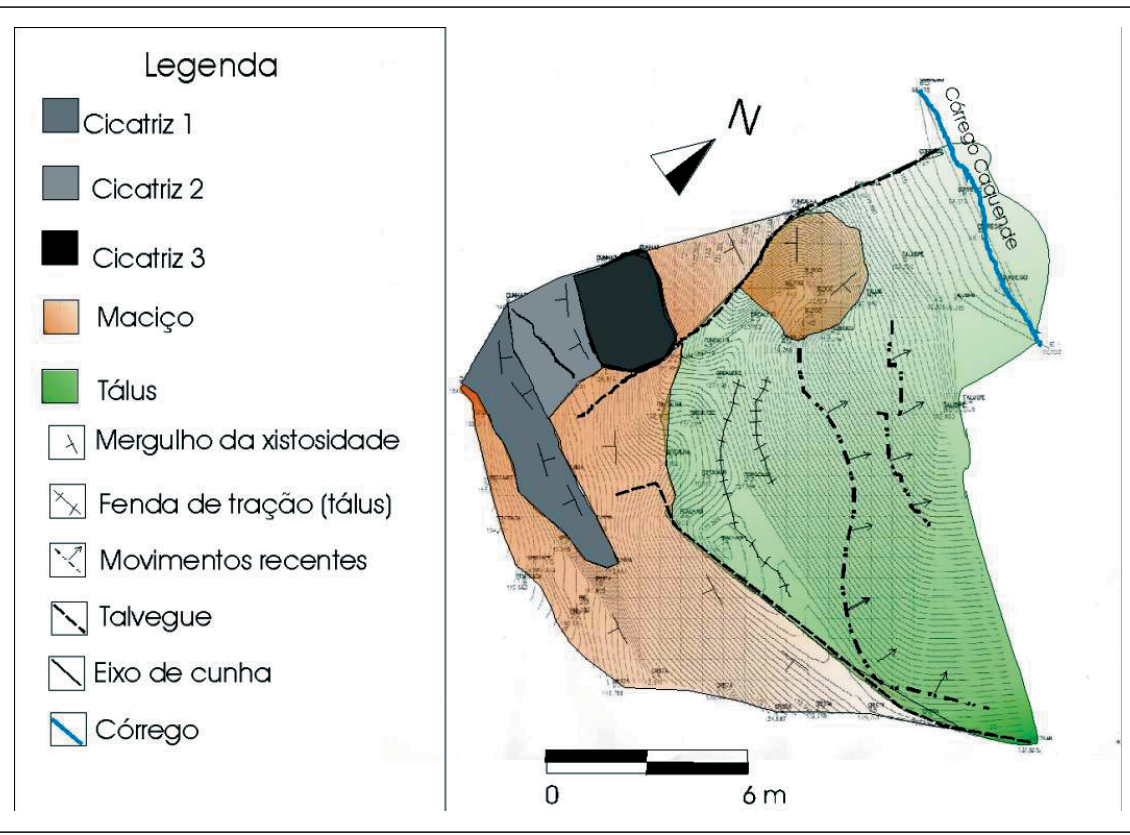

Figura 6 - Mapa geotécnico da área estudada. 


\subsection{Identificação dos mecanismos de ruptura}

A análise cinemática para identificação dos mecanismos de ruptura foi feita através das projeções estereográficas, utilizando-se do programa DIPS 5.079 .

Os resultados das análises cinemáticas e das observações de campo, apesar da proximidade entre as cicatrizes, indicaram a ocorrência de dois mecanismos de ruptura diferentes nas cicatrizes 1 e 2; planar, segundo a xistosidade, e em cunha, segundo a interseção entre a xistosidade e a família $1 \mathrm{~m}$, respectivamente.

A variabilidade na atitude da xistosidade observada durante o estudo ocorre devido aos dobramentos locais. Nas duas cicatrizes estudadas, essa variação de atitude é significativa, o que não era de se esperar devido à proximidade das mesmas. Essa variabilidade leva à ocorrência dos dois mecanismos de ruptura diferentes.

Numa cicatriz, a xistosidade tem atitude média 094/32 (1) e, na outra, 167/42 (2), ver Figura 8. Essa variação é decorrente da presença de um dobramento local, sendo as cicatrizes desenvolvidas uma em cada flanco da dobra. No flanco 1 , correspondente à xistosidade de atitude média 094/32, o mecanismo de ruptura é planar segundo o plano de xistosidade. No flanco 2, correspondente à xistosidade de atitude média 167/42, o mecanismo de ruptura é em cunha segundo a interseção do plano de xistosidade com a família $1 \mathrm{~m}$.

Na Figura 9, é representado de maneira esquemática o dobramento local que deu origem às rupturas. A ruptura planar segundo a xistosidade ocorre no flanco esquerdo da dobra, enquanto que no flanco direito ocorre a ruptura em cunha (ver Figuras 8 e 9).

Merece destaque o fato de que a análise cinemática foi feita utilizando-se os valores médios das atitudes das descontinuidades. Em situações-limites, ou seja, naqueles casos onde é possível a ocorrência de mais de um tipo de ruptura potencial, qualquer variação nos valo-

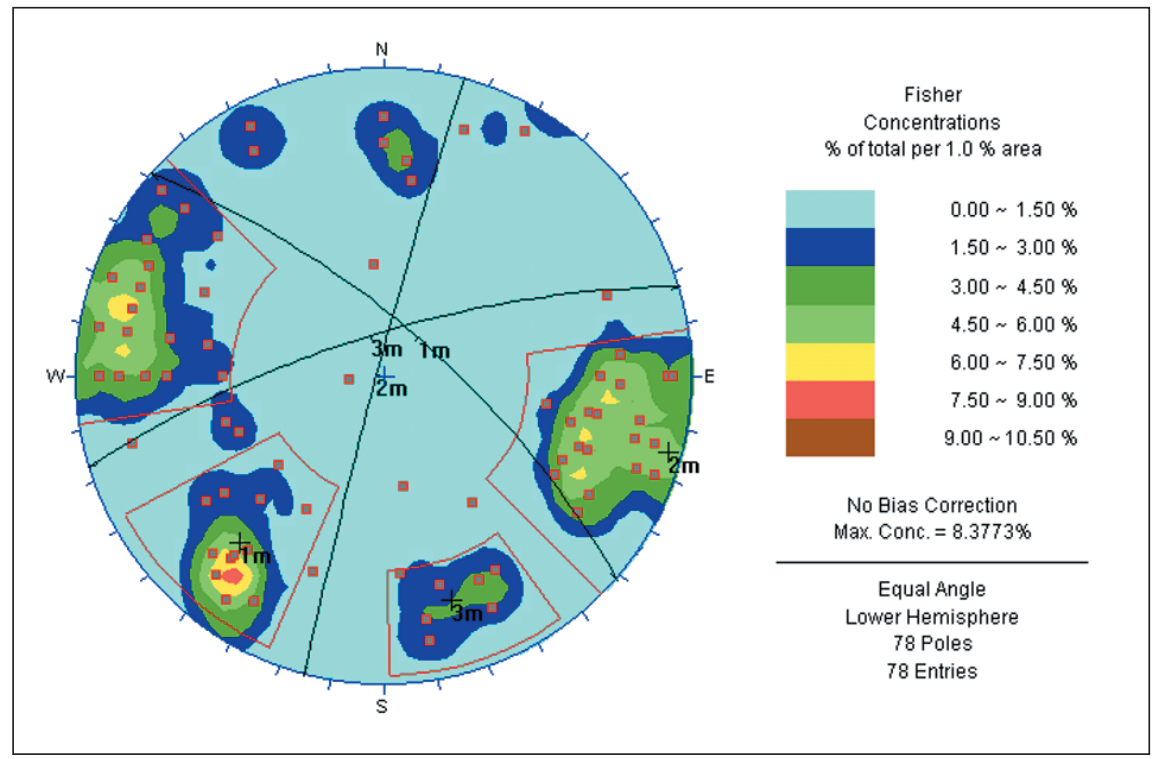

Figura 7 - Famílias de fraturas identificadas (DIPS 5.079).

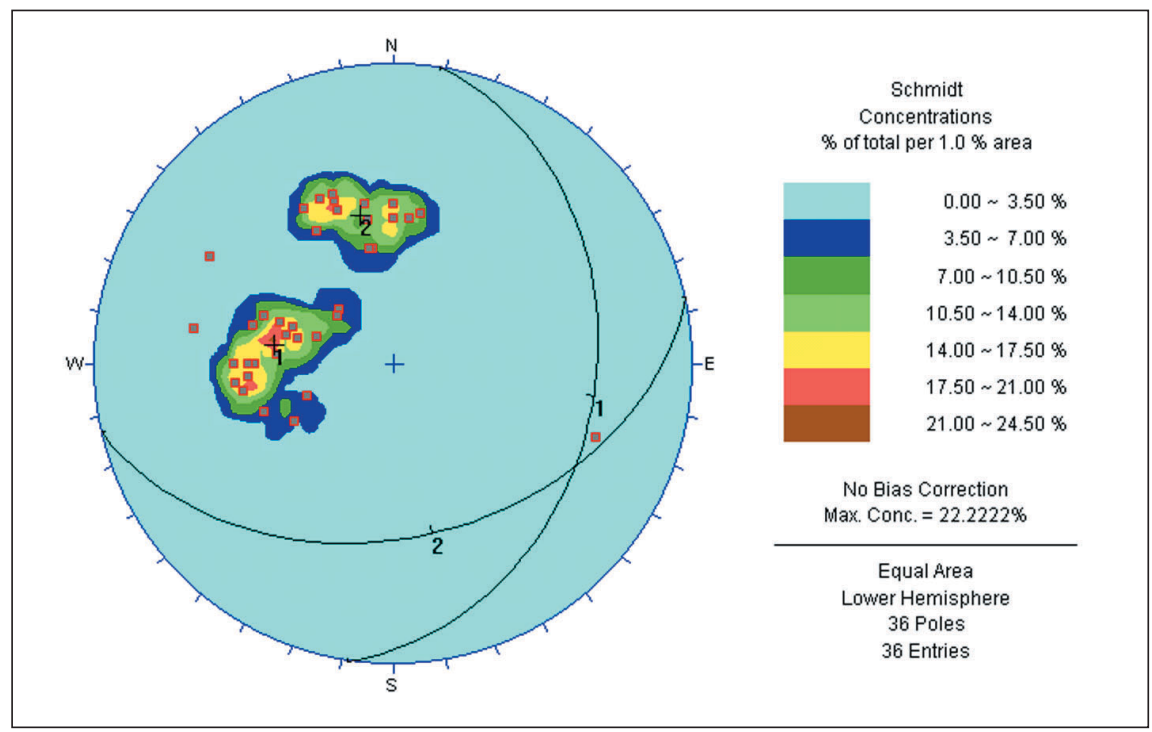

Figura 8 - Diagrama de freqüência de pólos mostrando variação da atitude da xistosidade nas cicatrizes (DIPS 5.079).

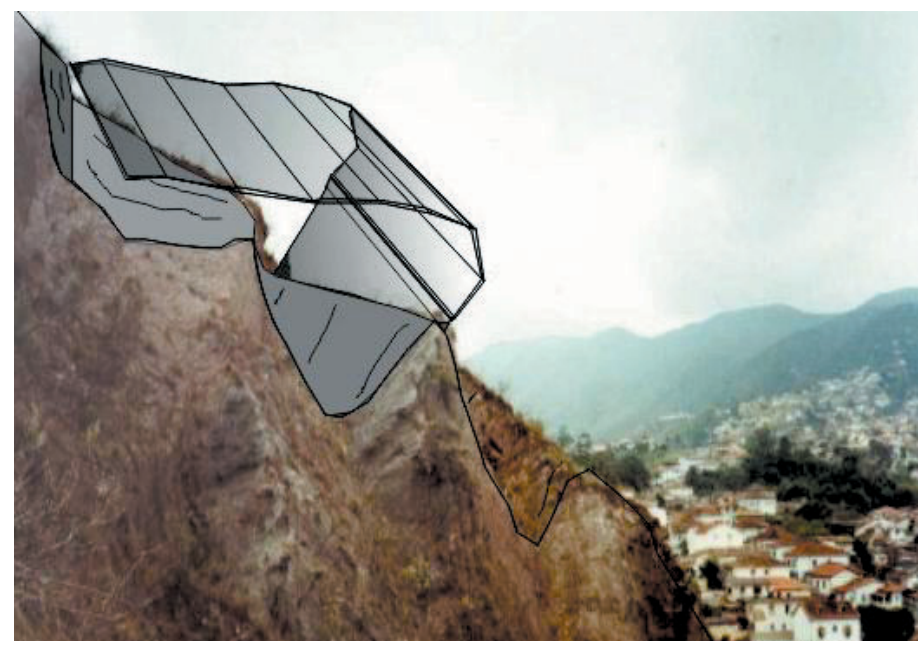

Figura 9 - Representação esquemática da dobra, mostrando os dois tipos de rupturas. 
res das atitudes das descontinuidades pode levar a resultados diferentes na análise cinemática.

A orientação do talude também tem grande influência nos resultados da análise cinemática. No caso analisado, o erro cometido na medição da orientação do talude pode chegar até $10^{\circ}$, em função da geomorfologia complexa da encosta.

A correta interpretação dos resultados dos mecanismos de ruptura só foi possível a partir das evidências de campo, observadas durante o levantamento geotécnico de detalhe.

\section{Considerações Finais}

O descaso e a omissão dos órgãos fiscalizadores responsáveis, aliados à falta de conscientização dos moradores, fazem com que o problema de risco geotécnico em Ouro Preto só aumente, já que, ao levar água e energia elétrica aos locais, criam-se condições para a ocupação de áreas de risco.

O que se tem observado, infelizmente, é que o problema de ocupação em áreas de risco só é discutido por todos (políticos, órgãos públicos responsáveis, população, imprensa), quando ocorrem catástrofes como a que ocorreu em ja- neiro de 2003, em Belo Horizonte. Após os períodos de grandes precipitações chuvosas, a população volta a ocupar as áreas de risco, os órgãos fiscalizadores relaxam a fiscalização e os demais cuidam de outros interesses, só voltando a preocupação com o problema quando as chuvas retornam.

Trabalhos como o de Fernandes (2000) e Pinheiro (2002) são importantes para gerar conhecimento acerca das características dos terrenos e podem servir de subsídio ao planejamento da ocupação urbana.

Há a necessidade de uma conscientização da população e principalmente dos órgãos públicos responsáveis de que o problema é grave. Deve-se priorizar o trabalho conjunto de todos (políticos, poder público, população, imprensa, instituições de ensino etc.) para que Ouro Preto continue sendo importante pelo seu patrimônio histórico, pelo potencial turístico de suas igrejas, museus, sua arte barroca, suas cachoeiras e não por tragédias que poderão vir a acontecer com as rupturas em suas encostas como já ocorreu aqui no passado e em diversas cidades brasileiras como Teresópolis, Petrópolis, Belo Horizonte, entre outras.

\section{Referências Bibliográficas}

DIPS 5.079. Rocscience Inc., 2002.

DORR II, J. V. N. Phisiographic, stratigraphic and structural development of the Quadrilátero Ferrífero, Minas Gerais, Brasil, technical report, DNPM/USGS, Washington, 1969. 109p.

FERNANDES, G. Caracterização geológicogeotécnica e proposta de estabilização da encosta do Morro do Curral - Centro de Artes e Convenções de Ouro Preto. Ouro Preto: UFOP, 2000. 136p. (Dissertação de Mestrado).

PINHEIRO, A. L. Análise de rupturas em taludes no Morro do Curral, Ouro Preto, MG. Ouro Preto: UFOP, 2002. 116p. (Dissertação de Mestrado).

LANA, M. S. Estudo dos mecanismos de ruptura em taludes de grande altura num maciço rochoso de geologia estrutural complexa. Belo Horizonte: UFMG, 2000. 211p. (Tese de Doutorado).

LANA, M. S., GRIPP, M. F. A. The use of inclined hemisphere projections for analyzing failure mechanisms in discontinuous rocks. Engineering Geology, v. 67, n. 3,2003 , p. $321-330$.

SOBREIRA, F. G., ARAÚJO, L. G., BONUCCELLI, T. J. Levantamento de soluções estruturais para a contenção de encostas em Ouro Preto. Relatório técnico. Convênio IPHAN/UFOP, Ouro Preto, MG, 1990. 91p.

SOBREIRA, F. G., FONSECA, M. A. Impactos físicos e sociais de antigas atividades de mineração em Ouro Preto, Brasil. Revista Geotecnia. n. 92, p.5-27, 2001.

\section{Artigo recebido em 11/07/2003 e} aprovado em 11/09/2003.

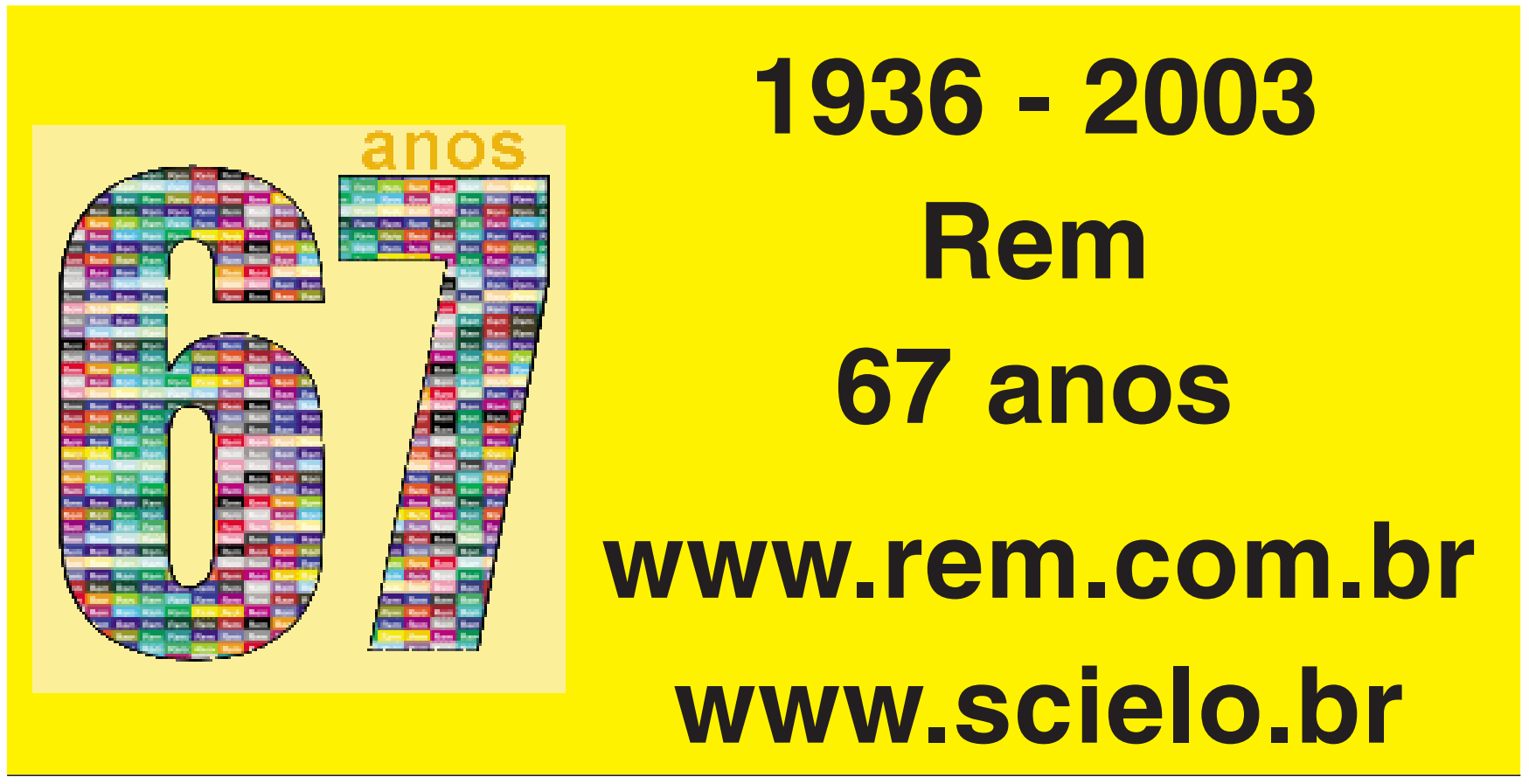

174 REM: R. Esc. Minas, Ouro Preto, 56(3): 169-174, jul. set. 2003 